\section{What is already known on this topic}

Evidence on the effectiveness of health system reforms is scarce

Studies have not used a consistent framework for specifying goals or measuring outcomes

\section{What this study adds}

Countries with the best levels of health do not always have efficient health systems

Efficiency is related to expenditure on health per capita, especially at low expenditure

The methods of measuring performance provide a basis for identifying policies that improve health and for monitoring reforms
5 Moore M. Public sector reform; downsizing, restructuring, improving performance. Geneva: World Health Organization, 1996 (Forum on health sector reform discussion paper 7).

6 Durham G, Kill B. Public health funding mechanisms in New Zealand. Aust Health Rev 1999:22:100-12.

7 Ron A. NGOs in community health insurance schemes: examples from Guatemala and the Philippines. Soc Sci Med 1999;48:939-50.

8 DeRosario JM. Healthcare system performance indicators: a new beginning for a reformed Canadian healthcare system. J Health Qual 1999;21:37-41.

9 World Health Organization. World Health Report 2000. Geneva: WHO, 2000.

10 Evans DB, Bendib L, Tandon A, Lauer JA, Ebener S, Hutubessy R, et al. Estimates of income per capita, literacy, educational attainment, absolute poverty, and income Gini coefficients for the World Health Report 2000. Geneva: World Health Organization, 2000. (Global programme on evidence for health Health Organization, 2000. (G
policy discussion paper No 7.)

11 Tengs TO, Adams ME, Pliskin JS, Safran DG, Siegel JE, Weinstein MC, et al. Five-hundred life-saving interventions and their cost-effectiveness. Risk Anal 1995; 15:369-90.

12 Murray CJL, Kreuser J, Whang W. Cost-effectiveness analysis and policy choices: investing in health systems. Bull World Health Org 1994;74:66374.

13 Murray CJL, Evans DB, Acharya A, Baltussen RM. Development of WHO guidelines on generalized cost-effectiveness analysis. Health Ecom 2000;9:235-51.

14 Caldwell JC. Education as a factor in mortality decline: an examination of Nigerian data. Pop Stud 1979;33:395-413.

system assessment framework. JAL estimated historical levels of health system attainment. All four authors revised the manuscript and approved the final version. Raymond Hutubessy, Yukiko Asada, and JAL researched historical income and education levels. Alan Lopez, Colin Mathers, Ritu Sadana, Josh Salomon, Omar Ahmad, and Doris Mafat estimated life expectancy and healthy life expectancy. Jean-Pierre Pouillier, Patricia Hernandez, and Chandika Indikadahena estimated health expenditure. Julio Frenk had a major input to the health system assessment framework. DBE is guarantor.

Funding: None.

Competing interests: None declared.

1 Maynard A, Bloor K. Health care reform: informing difficult choices. Int J Health Plann Manage 1995;10:247-64

2 Collins C, Green A, Hunter D. Health sector reform and the interpretation of policy context. Health Policy 1999;47:69-83.

Hussein AK, Mujinja PG. Impact of user charges on government health facilities in Tanzania. East Afr Med J 1997;74:751-7.

4 Feldman R. The ability of managed care to control health care costs: how much is enough? J Health Care Finance 2000;26:15-25.
15 Caldwell JC, Caldwell P. Education and literacy as factors in health. In: Halstead SB, Walsh JL, Warren KS, eds. Good health at low cost. New York: Rockefeller Foundation, 1985:181-5.

16 Evans D, Tandon A, Murray CJL, Lauer J. The comparative efficiency of national health systems in producing health: an analysis of 191 countries. Geneva: World Health Organization, 2000. (Global programme on evidence for health policy discussion paper No 29.)

17 Halstead SB, Walsh JA, Warren KS, eds. Good health at low cost. New York: Rockefeller Foundation, 1985

18 Hsiao W. What should macroeconomists know about health care policy? A primer. Washington, DC: International Monetary Fund, 2000. (IMF working paper.)

19 Ahmad OB, Lopez AD, Inoue M. The decline in child mortality: a reappraisal. Bull World Health Org 2000;78:1175-9.

20 Tengs TO. Dying too soon: how cost-effectiveness analysis can save lives. Dallas, TX: National Center for Policy Analysis, 1997. (NCPA policy report No 204.)

21 Tandon A, Murray CJL, Lauer J, Evans D. Measuring overall health system per(Global programme on evidence for health policy discussion paper No 30.) (Accepted 17 April 2001) formance for 191 countries. Geneva: World Health Organization, 2000

\title{
Influence of variation in birth weight within normal range and within sibships on IQ at age 7 years: cohort study
}

Thomas D Matte, Michaeline Bresnahan, Melissa D Begg, Ezra Susser

\begin{abstract}
Center for Urban Epidemiologic Studies, New York Academy of Medicine, 1216

Fifth Avenue, New York, NY 10029, USA

Thomas D Matte senior epidemiologist
\end{abstract}

continued over

BMJ 2001;323:310-4

\begin{abstract}
Objective To examine the relation between birth weight and measured intelligence at age 7 years in children within the normal range of birth weight and in siblings.

Design Cohort study of siblings of the same sex. Setting 12 cities in the United States.

Subjects 3484 children of 1683 mothers in a birth cohort study during the years 1959 through 1966. The sample was restricted to children born at $\geqslant 37$ weeks gestation and with birth weights of 1500-3999 g.
\end{abstract}

Main outcome measure Full scale IQ at age 7 years. Results Mean IQ increased monotonically with birth weight in both sexes across the range of birth weight in a linear regression analysis of one randomly selected sibling per family $(\mathrm{n}=1683)$ with adjustment for maternal age, race, education, socioeconomic status, and birth order. Within same sex sibling pairs, differences in birth weight were directly associated with differences in IQ in boys (812 pairs, predicted IQ difference per $100 \mathrm{~g}$ change in birth weight $=0.50$, $95 \%$ confidence interval 0.28 to 0.71 ) but not girls (871 pairs, $0.10,-0.09$ to 0.30 ). The effect in boys remained after differences in birth order, maternal smoking, and head circumference were adjusted for and in an analysis restricted to children with birth weight $\geqslant 2500 \mathrm{~g}$.

Conclusion The increase in childhood IQ with birth weight continues well into the normal birth weight range. For boys this relation holds within same sex sibships and therefore cannot be explained by confounding from family social environment.

\section{Introduction}

Many studies have shown that children born at low birth weight $(<2500 \mathrm{~g})$ have deficits in average intelligence test scores at school age. ${ }^{1}$ Within the low birth 
weight range, children who are smaller at birth have larger deficits than those closer to normal birth weight. $^{23}$ The effect seems to be similar for both performance and verbal IQ. ${ }^{1}$

Recent studies, as well as some earlier reports, have suggested that the direct relation of birth weight to measured intelligence continues well into the normal range of birth weight. ${ }^{4-8}$ However, these studies have not fully controlled for potential confounders, the most important of which is family social environment. Moreover, two early studies raise questions about the relation. Record et al found an association between birth weight and verbal reasoning scores in a birth cohort overall, but not within sibships, suggesting that the association was confounded by family environment. ${ }^{7}$ A study of the Dutch famine showed that maternal starvation during pregnancy lowered birth weight but not IQ. ${ }^{9}$

Although the reported effects of variation within normal birth weight on IQ are modest and of no clinical importance for individual children, they could be important at a population level because of the large proportion of children born of normal weight. In addition, these effects could shed light on links between fetal growth and brain development. We therefore sought to confirm the association between individual birth weight and childhood IQ using data from the National Collaborative Perinatal Project. ${ }^{10}$ We also examined the relation of birth weight to IQ within families.

\section{Methods}

The National Collaborative Perinatal Project was established to study the relation between prenatal factors, labour and delivery, and child development through to age 7 years. About 40000 women were enrolled, and follow up of about 58000 pregnancies was initiated from 1959 to 1966 at 12 medical centres across the United States. The methods have been previously described. ${ }^{11}$ We used the archival public data set for this analysis. ${ }^{12}$

\section{Sample}

To examine the relation between variation in birth weight and IQ, we constructed a sibship sample from children meeting specific inclusion criteria. The criteria were singleton birth, birth order less than 5, birth weight 1500-3999 $\mathrm{g}$, gestational age $\geqslant 37$ weeks, and living at age 7 . These restrictions aimed to reduce the influence of factors other than fetal growth (for example, birth order, gestational age) on any association between birth weight and IQ. The sibship sample was further restricted to those families that could contribute at least two eligible siblings of the same sex. Families that could contribute sibships of both sexes (two boys and two girls) were dropped to preserve independence among sibships (36 children from nine families). We also excluded families in which any eligible sibling had a serious malformation of the cardiovascular or central nervous system.

The full sibship sample included 3484 children from 1683 families. Of these 1683 families, 1567 contributed two siblings, 114 contributed three siblings, and two contributed four siblings of the same sex. Compared with all births in the database, children in the sibship sample were from families with a slightly higher than average socioeconomic index (50 $v 47$ on a scale of 0 to 100 that reflects household income and education and occupation of the head of household ${ }^{13}$ ), were more likely to have white mothers $(61 \% v 45 \%)$, and were more likely to be born to mothers under 20 years of age $(27 \% v 23 \%)$.

We drew two samples from the full sibship sample. The one sib sample comprised one sibling, chosen at random, from each family $(\mathrm{n}=1683 ; 871$ girls and 812 boys). The two sib sample comprised all sibling pairs from families contributing only two children, plus pairs chosen at random from larger sibships $(n=3366 ; 1742$ girls and 1624 boys).

\section{Measurement of intelligence}

Children enrolled in the National Collaborative Perinatal Project had periodic developmental and neuropsychological assessments from birth through to age 7 years. The intelligence tests administered at age 7 included four of five verbal and three of five performance tests from the Wechsler intelligence scale for children. ${ }^{14}$ We used the full scale IQ score that was constructed from the seven subtests administered, with equal weight given to verbal and performance tests.

\section{Statistical analysis}

We used linear regression to model the relation of birth weight to IQ in the one sib sample. Birth weight was treated first as a continuous variable and then as a categorical variable, with categories defined as 1500$2499 \mathrm{~g}, 2500-2999 \mathrm{~g}, 3000-3499 \mathrm{~g}$, and 3500-3999 g. Because the distribution of birth weight differs between boys and girls, we fitted separate models for each sex. We included the following potential confounders as covariates: maternal race (white/non-white), family socioeconomic index (average score reported across pregnancies), maternal education (highest number of

\begin{tabular}{|c|c|c|c|}
\hline Categories & $\begin{array}{l}\text { No (\%) of } \\
\text { children }\end{array}$ & $\begin{array}{l}\text { Mean birth } \\
\text { weight }(g)\end{array}$ & $\begin{array}{l}\text { Mean ful } \\
\text { scale IQ }\end{array}$ \\
\hline \multicolumn{4}{|l|}{ Sex: } \\
\hline Male & $1690(49)$ & 3233 & 97.4 \\
\hline Female & $1794(51)$ & 3143 & 97.2 \\
\hline \multicolumn{4}{|l|}{ Birth order: } \\
\hline 1 & 907 (26) & 3144 & 97.7 \\
\hline 2 & $1269(36)$ & 3208 & 98.2 \\
\hline 3 & $891(26)$ & 3179 & 96.2 \\
\hline 4 & 417 (12) & 3229 & 96.1 \\
\hline \multicolumn{4}{|l|}{ Maternal age: } \\
\hline 11-19 & $953(27)$ & 3144 & 92.2 \\
\hline $20-29$ & $2234(64)$ & 3204 & 99.0 \\
\hline$\geqslant 30$ & $297(9)$ & 3194 & 100.8 \\
\hline \multicolumn{4}{|l|}{ Maternal education: } \\
\hline Below high school & $1715(49)$ & 3135 & 92.3 \\
\hline High school graduate & $1367(39)$ & 3228 & 99.7 \\
\hline Some after high school & $253(7)$ & 3267 & 107.6 \\
\hline College graduate & $149(4)$ & 3269 & 115.3 \\
\hline \multicolumn{4}{|l|}{ Race: } \\
\hline White & $2108(61)$ & 3236 & 102.4 \\
\hline All others* & $1376(39)$ & 3111 & 89.5 \\
\hline \multicolumn{4}{|l|}{ Birth weight $(\mathrm{g})$} \\
\hline$<2500$ & $187(5)$ & 2303 & 91.9 \\
\hline $2500-999$ & $892(26)$ & 2798 & 94.5 \\
\hline $3000-499$ & $1578(45)$ & 3240 & 97.7 \\
\hline $3500-999$ & $827(24)$ & 3705 & 100.7 \\
\hline
\end{tabular}

${ }^{*} 98.2 \%$ are black; the remainder are Hispanic, Asian, other, or unknown.
Department of Epidemiology, Mailman School of Public Health, Columbia

University, 622 Wes 168th Street, New York, NY 10032 USA

Michaeline

Bresnahan assistant professor Ezra Susser professor

Division of Biostatistics, Mailman School of Public Health

Melissa D Begg associate professor

Correspondence to: T D Matte tmatte@nyam.org 
Table 2 Means and correlations of continuous variables for sibship sample $(n=3484)$

\begin{tabular}{lccc} 
& Mean & Correlation with birth weight & Correlation with IQ \\
\hline Socioeconomic index & 50 & 0.12 & 0.48 \\
\hline Birth weight $(\mathrm{g})$ & 3187 & 1.00 & 0.17 \\
\hline Full scale IQ & 97.3 & 0.17 & 1.00 \\
\hline
\end{tabular}

${ }^{*}$ Socioeconomic index was missing for six children (three families).

years maternal education reported across pregnancies), maternal age at birth, and birth order.

We used the two sib sample to assess the relation of birth weight to IQ within sibling pairs. We fitted a series of linear regression models, specifying IQ difference between siblings as a function of their difference in birth weight. (IQ and birthweight differences were computed after randomly assigning the order of the siblings in each pair.) Difference in birth weight was considered first as a continuous variable and then as a categorical variable $(<-500 \mathrm{~g} ;-500$ to $-200 \mathrm{~g}$; -200 to $200 \mathrm{~g}$; 200 to $500 \mathrm{~g}$; and $>500 \mathrm{~g}$ ). To reduce potential confounding by pregnancy specific factors, we fitted separate models with adjustments for differences in birth order, maternal smoking, and head circumference. Difference in birth order was defined as a binary variable in two ways: younger versus older, and firstborn versus not. Difference in maternal smoking during pregnancy was defined as concordant $(+/+$, $-/-)$ or discordant in two distinct categories $(+/-$ and $-/+)$. Finally, to ensure that any associations observed were not accounted for by the inclusion of low birthweight children, we repeated the analyses using only those sibling pairs in which both siblings had birth weights of $\geqslant 2500 \mathrm{~g}$.

\section{Results}

Tables 1 and 2 provide descriptive data for the sibship sample on all variables used in the analyses and their crude relations with birth weight and IQ. Birth weight and IQ relate to measures of social disadvantage in the expected direction. Lower birth weights and lower IQs were seen in mothers of younger age, lower education, non-white race, and lower socioeconomic index. Mean

Table 3 Summary of linear regression models of relation of birth weight to IQ in one sib sample (871 girls and 812 boys for crude analyses; 869 girls and 811 boys for adjusted analyses)

\begin{tabular}{|c|c|c|}
\hline \multirow[b]{2}{*}{ Birth weight variable $(\mathrm{g})$} & \multicolumn{2}{|c|}{ Estimated coefficient } \\
\hline & Crude & Adjusted $^{*}(95 \% \mathrm{CI})$ \\
\hline \multicolumn{3}{|l|}{ Boys } \\
\hline Continuous† & 0.77 & $0.46(0.25$ to 0.66$)$ \\
\hline \multicolumn{3}{|l|}{ Categoricalł: } \\
\hline $1500-2499$ & -6.6 & $-3.7(-8.0$ to 0.6$)$ \\
\hline $2500-2999$ & -4.9 & $-2.2(-4.4$ to -0.07$)$ \\
\hline $3000-3499$ & 1.0 & 1.0 \\
\hline $3500-3999$ & 3.6 & $2.2(0.2$ to 4.2$)$ \\
\hline \multicolumn{3}{|l|}{ Girls } \\
\hline Continuous† & 0.63 & $0.28(0.09$ to 0.47$)$ \\
\hline \multicolumn{3}{|l|}{ Categoricalł: } \\
\hline $1500-2499$ & -5.7 & $-2.8(-5.8$ to 0.3$)$ \\
\hline 2500-2999 & -3.6 & $-2.1(-4.0$ to -0.3$)$ \\
\hline $3000-3499$ & 1.0 & 1.0 \\
\hline $3500-3999$ & 4.2 & $1.5(-0.6$ to 3.5$)$ \\
\hline
\end{tabular}

*Adjusted for race (white, non-white), mother's education, mother's age, family socioeconomic index, and birth order.

†IQ difference per $100 \mathrm{~g}$ difference in birth weight.

†Estimated average IQ difference compared with reference birth weight category.
IQ increased in roughly even increments across the birthweight categories examined.

Table 3 summarises the regression results from the analysis using the one sib sample. In both boys and girls, the association between IQ and birth weight is significant, although it is reduced by adjustment for familial factors. The association is stronger in boys than girls. For example, a $1000 \mathrm{~g}$ increase in birth weight relates to a 4.6 point increase in IQ among boys but only 2.8 points in girls. The associations remained significant when birth weight was treated as a categorical variable, even after important covariates were adjusted for $(\mathrm{P}=0.0012$ in boys; $\mathrm{P}=0.007$ in girls).

Table 4 Linear regression of within family differences in $I Q$ on within family differences in birth weight in two sib sample

\begin{tabular}{lc} 
Difference in birth weight $\mathbf{( g )}$ & Estimated coefficient $\mathbf{( 9 5 \%} \mathbf{~ C I})^{*}$ \\
\hline Boys (812 pairs) & $0.50(0.28$ to 0.71$)$ \\
\hline Continuous* & \\
\hline Categoricalt: & $-6.2(-9.3$ to -3.1$)$ \\
\hline-1900 to -500 & $-1.7(-4.3$ to 0.9$)$ \\
\hline-500 to -200 & 1.0 \\
\hline-200 to 200 & $-1.3(-3.8$ to 1.2$)$ \\
\hline 200 to 500 & $3.6(0.5$ to 6.7$)$ \\
\hline 500 to 1502 & \\
\hline Girls (871 pairs) & $0.10(-0.09$ to 0.30$)$ \\
\hline Continuous ${ }^{*}$ & \\
\hline Categoricalt: & $0.5(-2.3$ to 3.3$)$ \\
\hline-1900 to -500 & $-0.9(-3.2$ to 1.5$)$ \\
\hline-500 to -200 & 1.0 \\
\hline-200 to 200 & $-1.2(-3.5$ to 1.2$)$ \\
\hline 200 to 500 & $2.4(-0.2$ to 5.1$)$ \\
\hline 500 to 1502 &
\end{tabular}

${ }^{*} \mathrm{Q}$ difference per birth weight difference of $100 \mathrm{~g}$.

†Estimated average IQ difference compared with reference category of birthweight difference.

Table 4 shows the results of the analysis on the two sib sample. Within sibling pairs of the same sex, IQ differences were directly related to differences in birth weight (heavier sibling having, on average, the higher IQ) when treated as a continuous variable. However, the slope of IQ difference by birthweight difference was about five times greater in boys than in girls, and the association was significant only in boys. To formally test whether sex modifies the association between birthweight difference and IQ difference, we fitted an interaction model using data from all 1683 sibling pairs. The interaction between sex and birthweight difference was significant $(\mathrm{P}=0.008)$.

Adjustment for differences in birth order and maternal smoking had no effect on the estimated effect of birth weight for either sex. Adjustment for differences in head circumference between siblings slightly reduced the effect of birth weight in boys $(0.44$, $95 \%$ confidence interval 0.17 to 0.70$)$ and girls $(-0.03$, -0.28 to 0.21 ).

Table 4 also gives estimated differences in IQ by categories of differences in birth weight. These results re-enforce findings from the continuous analysis, showing a significant difference across categories of birthweight difference in boys $(\mathrm{P}<0.001)$ but not in girls $(\mathrm{P}=0.17)$.

All analyses in table 4 were repeated in the subsample of pairs where both siblings had birth weights $\geqslant 2500 \mathrm{~g}$. The findings were essentially identical to those based on the entire two sib sample. 


\section{Discussion}

Our results add to the evidence that the association between IQ and birth weight continues well into the normal range of birth weight. ${ }^{4-7}$ We have shown that this association is not explained by confounding from unmeasured or poorly measured social or maternal factors. The relation within sibships of birth weight to IQ we observed in boys was tightly controlled for such factors.

\section{Comparison with other studies}

Our results for the one sib sample are similar to those in recent reports. Richards et al found an association between birth weight and cognitive ability at age 8 across the normal range of birth weight in the British 1946 birth cohort. ${ }^{4}$ Breslau et al also found birth weight was associated with IQ at age 6 in a sample of several hundred low and normal birthweight children and that the association extended into the range of normal birth weights. ${ }^{5}$

In the only other study of birth weight and intelligence in siblings who were mostly of normal birth weight, Record et al did not find the associations we report. ${ }^{7}$ Differences between their result and ours may be due to differences in the intelligence score used (we used full scale IQ and they used verbal reasoning scores from school examinations) or in the exclusion criteria (Record et al did not exclude preterm births or high birth order siblings).

The difference between boys and girls is puzzling and needs replication. A recent report noted sex differences in the relation of body measurements at birth to coronary artery disease in adult life. The authors postulated that sex differences in fetal growth rates (with growth generally being slower among girls) could lead to different responses to fetal undernutrition. ${ }^{15}$ Hormonally mediated sex differences in prenatal brain development could also have a role. ${ }^{16}$

The National Collaborative Perinatal Project is a thoroughly analysed data set, and our findings should also be compared with previous analyses. An unadjusted analysis found an association of IQ with birth weight well into the normal range, consistent with our adjusted one sib analysis. ${ }^{8}$ In an analysis of a smaller subsample of sibling pairs, however, 148 low birthweight children had slightly lower mean IQ than their same sex, normal birthweight siblings; the difference was not significant except in low birthweight children with small head circumference at birth. ${ }^{17}$ We found that differences in head circumference did not explain the association between birth weight and IQ. One explanation of our finding is that head circumference is not sensitive to any subtle influence of fetal growth restriction on brain development. In addition, compared with birth weight, head circumference varies less between individuals and is less precisely measured.

\section{Importance of association}

At least two studies suggest that the relation we observed between birth weight and IQ might persist into adult life. Richards et al found a gradient relation of birth weight to covariate adjusted cognitive test scores from childhood through age 26 in the 1946 birth cohort. Sorensen et al linked birth records to cognitive test results among 4300 Danish men being evaluated for military service and found a positive

\section{What is already known on this topic}

IQ at school age is linked to birth weight among low birthweight babies

Some evidence suggests the association might also apply to children of normal birth weight

\section{What this study adds}

IQ at age 7 years is linearly related to birth weight among children of normal birth weight

The relation was not due to confounding by maternal or socioeconomic factors

IQ is also associated with differences in birth weight between boy sibling pairs but not girls

relation for birth weights up to about $4200 \mathrm{~g} .{ }^{6}$ These results suggest an effect size of about a 0.2 standard deviation increase in mean adjusted cognitive test score per $1 \mathrm{~kg}$ increase in birth weight. This is similar to our findings. In each of these studies, however, control for potentially confounding influences, such as the home environment, relied on proxy measures such as social class and maternal education and may therefore have been incomplete.

From a clinical point of view, the effect in our study of even a $1 \mathrm{~kg}$ difference in birth weight is trivial. At the population level, however, more than seven times as many children are born with birth weights between 2500 and $3499 \mathrm{~g}$ than are born with low birth weight. ${ }^{18}$ Small shifts in the distribution of birth weight among normal birthweight babies might have greater impact on the population distribution of intelligence than larger shifts in the percentage of babies born at low birth weight. It may therefore be important to identify the sources of variation in birth weight that are both amenable to intervention and linked to improved cognitive ability.

From a scientific point of view, our findings may have important implications for future research on the connections between fetal growth and brain development. Considerable efforts continue to be directed at understanding causes of low birth weight, its neurodevelopmental consequences, and the mechanisms linking the two. Evidence from this and other studies suggests that these efforts should be broadened to examine the influences on fetal growth among those with normal birth weight and the neurodevelopmental implications of such variation.

We thank Marcus Richards and Sander Greenland for their comments.

Contributors: TDM and ES developed the initial study idea. MB and MDB helped to develop the idea. MBD designed the statistical analysis with input from all authors, and conducted it with MB. MB compiled and cleaned the sibship data files. The paper was jointly written by all authors. TDM and ES will act as guarantors.

Funding: New York Community Trust.

Competing interests: None declared.

1 Breslau N. Psychiatric sequelae of low birth weight. Epidemiol Rev 1995;17:96-106.

2 McCormick MC, Brooks-Gunn J, Workman-Daniels K, Turner J, Peckam GJ. The health and developmental status of very low-birth-weight children at school age. JAMA 1992;267:2204-8.

3 Breslau N, DelDotto JE, Brown GG, Kumar S, Ezhuthachan S, Hufnagle $\mathrm{KG}$, et al. A gradient relationship between low birth weight and IQ at age 6 years. Arch Pediatr Adolesc Med 1994;148:377-83. 
4 Richards M, Hardy R, Kuh D, Wadsworth MEJ. Birthweight and cognitive function in the British 1946 birth cohort: longitudinal population based study. BMJ 2001;322:199-203.

5 Breslau N, Chilcoat H, DelDotto J, Andreski P, Brown G. Low birth weight and neurocognitive status at six years of age. Biol Psychiatry 1996;40: 389-97.

6 Sorensen HT, Sabroe S, Olsen J, Rothman KJ, Gillman MW, Fisher P. Birth weight and cognitive function in young adult life: historical cohort study. BMJ 1997;315:401-3

7 Record RG, McKeown T, Edwards JH. The relation of measured intelligence to birth weight and duration of gestation. Ann Hum Genet Lond 1969;33:71-9.

8 Hardy JB, Mellits ED. Relationship of low birth weight to maternal characteristics of age, parity, education , and body size. In: Reed DM, ed. The epidemiology of prematurity: epidemiology workshop, National Institute of Child Health and Human Development,1976. Baltimore: Urban and Schwarzenberg, 1977.

9 Stein ZA, Susser M, Saenger G, Marolla F. Famine and human development: the Dutch hunger winter of 1944/45. Oxford University Press: New York, 1975 .

10 Niswander NR, Gordon M. The women and their pregnancies. Philadelphia: WB Saunders, 1972
11 Broman S. The collaborative perinatal project: an overview. In: Mednick SA, Finello KM, eds. Handbook of longitudinal research. Vol 1. New York: Prager Publishers, 1984.

12 Collaborative Perinatal Project Electronic Records. Records of the National Institute of Neurological Disorders and Stroke 1950-88. College Park, MD: National Archives at College Park, 1958-84 (record group 443.8).

13 Myrianthopoulos NC, French KS. An application of the US Bureau of the Census socioeconomic index to a large diversified patient population. Soc Sci Med 1968;2:283-99

14 Wechsler D. Wechsler intelligence scale for children-manual. New York: Psychological Corporation, 1949.

15 Forsen T, Ericksson JG, Osmond C, Barker DJP. Growth in utero and during childhood among women who develop coronary heart disease: longitudinal study. BMJ 1999;319:1403-7.

16 Hutchison JB. Gender-specific steroid metabolism in neural differentiation. Cell Mol Neurobiol 1997;17:603-26.

17 Strauss RS, Dietz WH. Growth and development of term children born with low birth weight: effects of genetic and environmental factors. J Pediatr 1998;133:67-72.

18 Ventura SJ, Martin JA, Curtin SC, Matthews TJ. Births: final data for 1997. Hyattsville, MD: National Center for Health Statistics, 1999. (National vital statistics reports vol 47, No 18 .

(Accepted 3 May 2001)

\title{
Simultaneous zinc and vitamin A supplementation in Bangladeshi children: randomised double blind controlled trial
}

\author{
Mohammad M Rahman, Sten H Vermund, Mohammad A Wahed, George J Fuchs, \\ Abdullah H Baqui, Jose O Alvarez
}

International

Centre for

Diarrhoeal Disease Research, PO Box 128, Dhaka 1000, Bangladesh

Mohammad M Rahman

associate scientist

Mohammad A

Wahed

associate scientist

George J Fuchs

director, clinical

sciences division

Abdullah H Baqui

scientist

Department of

Epidemiology and

International

Health, School of

Public Health,

University of

Alabama at

Birmingham, AL

35294, USA

Sten H Vermund

professor

Jose O Alvarez

professor

Correspondence to:

M M Rahman,

Division of

Infectious Diseases

and Geographic

Medicine, Stanford

University School of

Medicine, 300

Pasteur Drive, S-025

Stanford, CA

94305-5107, USA

mujib_99@yahoo.com

BMJ 2001;323:314-8

\begin{abstract}
Objective To evaluate the effect of simultaneous zinc and vitamin A supplementation on diarrhoea and acute lower respiratory infections in children.

Study design Randomised double blind placebo controlled trial.

Setting Urban slums of Dhaka, Bangladesh.

Participants and methods 800 children aged 12-35 months were randomly assigned to one of four intervention groups: $20 \mathrm{mg}$ zinc once daily for 14 days; 200000 IU vitamin A, single dose on day 14; both zinc and vitamin A; placebo. The children were followed up once a week for six months, and morbidity information was collected.

Results The incidence and prevalence of diarrhoea were lower in the zinc and vitamin A groups than in the placebo group. Zinc and vitamin A interaction had a rate ratio $(95 \%$ confidence interval) of 0.79 ( 0.66 to 0.94 ) for the prevalence of persistent diarrhoea and $0.80(0.67$ to 0.95$)$ for dysentery. Incidence (1.62; 1.16 to 2.25$)$ and prevalence $(2.07 ; 1.76$ to 2.44$)$ of acute lower respiratory infection were significantly higher in the zinc group than in the placebo group. The interaction term had rate ratios of 0.75 (0.46 to 1.20$)$ for incidence and 0.58 (0.46 to 0.73 ) for prevalence of acute lower respiratory infection.

Conclusions Combined zinc and vitamin A synergistically reduced the prevalence of persistent diarrhoea and dysentery. Zinc was associated with a significant increase in acute lower respiratory infection, but this adverse effect was reduced by the interaction between zinc and vitamin $\mathrm{A}$.
\end{abstract}

\section{Introduction}

Trials of vitamin A supplementation have consistently shown a beneficial effect on childhood mortality, ${ }^{1-4}$ but the effect of vitamin A on morbidity is unclear. In some studies, the incidences of diarrhoea and respiratory infections were reduced with vitamin A supplementation. ${ }^{5}{ }^{6}$ Other studies have reported an effect on diarrhoea but no effect on respiratory infection. ${ }^{78} \mathrm{Sev}-$ eral studies have failed to show that vitamin A supplementation reduces morbidity. ${ }^{9-12}$ One possible explanation for the inconsistent findings is that multiple nutrient deficiencies affect the bioavailability of vitamin A and thereby prevent its beneficial effect. Among these micronutrient deficiencies, zinc is a likely suspect because of its interaction with vitamin A. ${ }^{13}$ Experimental studies have shown that serum retinol concentration is reduced in zinc deficient animals, and vitamin A supplementation failed to increase the low serum retinol to a normal concentration. ${ }^{14}$ However, when the animals were supplemented with zinc, either alone or in combination with vitamin A, the serum retinol concentration increased. In children with severe protein energy malnutrition, zinc supplementation improved serum retinol binding protein and retinol concentration. ${ }^{15}$ Deficiencies of zinc and vitamin A often coexist in malnourished children, so supplementation with zinc might overcome the failures with vitamin A supplementation observed in several studies.

We hypothesised that combining zinc with vitamin A supplementation would result in improved vitamin A status, reduced morbidity, and increased growth. We report the effect of supplementation with simultaneous zinc and vitamin A on the prevalence of diarrhoea and acute lower respiratory infection in children. 